TECHNICAL TRANSACTIONS 4/2017

CZASOPISMO TECHNICZNE 4/2017

PHYSICS

DOI: $10.4467 / 2353737$ XCT.17.062.6373

Wojciech Otowski (wotowski@fizyk.ifpk.pk.edu.pl)

\title{
Gabriela Lewińska
}

Institute of Physics, Faculty of Physics, Mathematics and Informatics, Cracow University

of Technology

\section{LIGHT SOURCES AND THEIR INFLUENCE ON VISION ORGAN}

\section{ŹRÓDŁA ŚWIATŁA I ICH WPŁYW NA NARZĄD WZROKU}

\section{Abstract}

The aim of the study was to compare light sources. The paper presents the spectrum of light intensity for natural and artificial sources. Analysis of the spectra was carried out because of their importance for the health of the eye.

Keywords: light source, spectrum analysis, electromagnetic radiation, the eye

\section{Streszczenie}

Celem artykułu jest porównanie źródeł światła. W pracy zostały zaprezentowane widma natężenia światła dla źródeł naturalnych i sztucznych. Przeprowadzona została analiza widm ze względu na ich znaczenie dla zdrowia narządu wzroku.

Słowa kluczowe: źródła światła, analiza widm, promieniowanie elektromagnetyczne, oko 


\section{Introduction}

All people are exposed to a certain dose of electromagnetic radiation (for instance sunlight). The influence of electromagnetic radiation on a person (the person's life and health) is significant. It can be both a positive and a destructive factor.

Ultraviolet light (ranging from $10 \mathrm{~nm}$ (extreme ultraviolet - EUV) to $400 \mathrm{~nm}$ (ultraviolet A - UVA)) activates changes in molecules, such as DNA, lipids and proteins. Near-infrared, infrared and far-infrared radiation $(700 \mathrm{~nm}-1 \mathrm{~mm})$ causes thermal activation or inactivation, coagulation, and change of phase. Light in the range from $180 \mathrm{~nm}$ to $400 \mathrm{~nm}$ may result in erythema, keratitis, conjunctivitis, cataract, retinitis, accelerated aging of the skin and skin cancer. Exposure to visible light (especially blue) may cause inflammation of the retina. Farinfrared radiation can cause thermal injury; denaturation of proteins and tissue coagulation. Blue light damage to the retina has research support. Ham was first to show that an exposure to $441 \mathrm{~nm}$ light produces a photochemical lesion at power levels too low to raise the retinal temperature by an appreciable amount $\left(<0.1^{\circ}\right)[1]$.

However, there is one more aspect connected with radiation still overlooked in studies. The light spectrum generated by artificial sources differs in shape from the solar spectrum. In many cases, for a very narrow wavelength range, we see peak(s); large increase of intensities. This means that, for a selected wavelength, the eye will accumulate excessive amounts of energy. This in turn leads to damage.

\subsection{The eye}

The human eye is an organ that reacts to visible light (400 to $700[\mathrm{~nm}]$ ). Due to photosensitive cells (namely rods and cones in the retina), incident light is converted into signals that are transformed by the brain into color images. Note that the cone sensitivity depends on the light intensity. In the process of seeing, the eyeball (bulbus oculi), which is responsible for the process of receiving the image, as well as elements of the nervous system, are responsible for transmitting the signal to the brain. The optic nerve needs a minimum energy of $10^{-17}[\mathrm{~J}]$ to induce a series of impulses in the brain. The photoreceptor cells contain photopigment molecules, which are transducers of light energy into biological response. Each photopigment molecule consists of two parts; a light sensitive chromophore (molecule derived from vitamin A (11-cis retinal)) and a protein backbone (helical stricture).

Each photoreceptor generates a baseline signal through the continuous transport of sodium ions $(\mathrm{Na}+)$ out of the inner segment of the cell and the import of potassium ions $(\mathrm{K}+)$ from the outside. At the same time, sodium ions can enter the outer segment via small pores. When the cell body is not exposed to light, the resulting ion imbalance produces a small, steady electric voltage of about $40[\mathrm{mV}]$ across the cell. Consequently, the so-called "dark current" (baseline signal) is produced. To create a nerve impulse, light "reduces" this baseline photoreceptor current [2].

When the chromophore is hit by a photon of the proper energy, it instantly changes shape (a photoisomerization effect). As a result, the opsin molecule also changes shape, which in 
turn changes the baseline electrical current across the cell body. This "simplified" process by which the retina translates light energy (from photon absorption) into nerve impulses (nerve output) is completed within 50 microseconds. Care must be taken that "the proper energy" means energy of photopigment (wavelength) peak sensitivity.

Each photopigment (photosensor) reacts with the highest probability on the proper energy photon. Reaction on other energy photons is less likely and requires a large number of photons (greater light intensity).

Human color vision is enabled by three types of photoreceptors:

- the scotopic band is represented by rod photoreceptors - it is monochromatic vision in very low light (night-vision),

- the photopic band is represented (primarily) by cone wavelength-dependent photoreceptors - it is color vision under suitably bright (well-lit, luminance level 10 to $10^{8} \mathrm{~cd} / \mathrm{m}^{2}$ ) conditions,

- the "meltopic" band which is a non-imaging photoreceptor - it is a stimulator of the biological clock [3].

In the late 1990's, the "meltopic" photoreceptor was recognized, which has sensitivity in the blue spectral range. It is the wavelength-dependent suppressor of melatonin production [4].

Research has found that exposure to bright white or blue light at night is associated with insomnia and increased risk for a wide range of diseases.

Due to light adaptation (or sensitivity regulation), the human eye can detect illuminance in the range of $10^{14}-$ from $10^{-6}[\mathrm{~lx}]$ to $10^{8}[\mathrm{~lx}]$ (note: midday sun is even $10^{9}[\mathrm{~lx}]-$ see Fig. 1) [5]. Spectral sensitivity is the relative efficiency of detection, of light or other signal, as a function of the frequency or wavelength of the signal [6]. It has been established that the maximum spectral sensitivity of the human eye under daylight conditions is at a wavelength of 555 [nm] (green), while at night the peak shifts to 507 [nm] (blue-green) [7]. Spectral sensitivity may be expressed as a quantum efficiency. Spectral response functions of the three human photoreceptors are presented in Fig. 2.

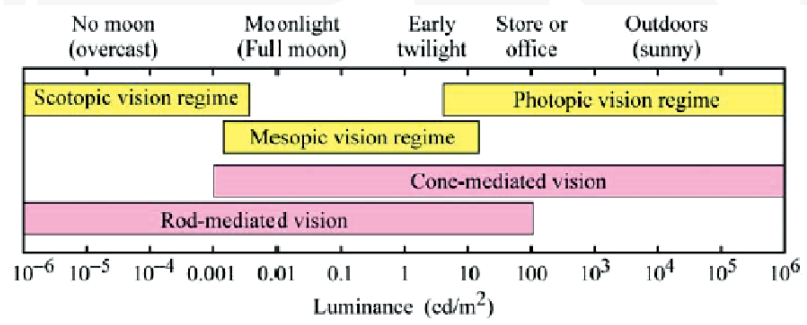

Fig. 1. Approximate luminance ranges of human vision and corresponding photoreceptors [5]

Much about it is the probability to catch light energy (a quantum of light) as a function of wavelength $[7,8]$. It may be expressed with units, such as amperes per watt [9-11]. However, the light adaptation mechanisms are not clear yet.

The responses of the rod and cone cells have a nonlinear dependence [6]. On the other hand, the light effective excitation of photopigment is rather linear [2]. 


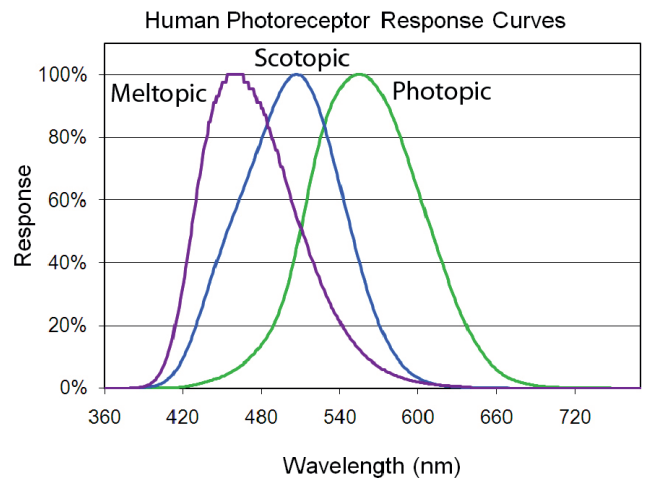

Fig. 2. Spectral response functions of the three human photoreceptor bands [6]

One should note that the signal of a photoreceptor representing light is transmitted through the nerve impulse as a change in the "dark current" [2]. The human eye reacts to the light incident on a physical surface (the illuminance) and/or emitted from a surface (the luminance). The comfort range for luminance is much smaller (from $10^{10}[\mathrm{~lx}]$ to $10^{40}[\mathrm{~lx}]$ ) compared to the illuminance. However, this is coherent with the fact that our visual system does not adapt to the actual illuminance. The retina has a static contrast ratio of around 100:1. As soon as the eye moves, it re-adjusts its exposure both chemically and geometrically. Hence, the dynamic contrast ratio amounts to about 1000 000:1. The rods are more sensitive and allow vision in low light conditions (so-called scotopic vision); they also have a great ability to perceive moving objects. Cones are responsible for color vision in bright light (also called photopic vision). The human system adapts to the average luminance (diffuse light). The light adaptation occurs relatively quickly.

There are two ways that light will damage your eye [12]:

1. Thermal damage when too much energy is concentrated on the retina. For visible and infrared light reaching the retina, melanin and haemoglobin are the primary absorbers. Power of $20[\mathrm{~mW}]$ is enough to cause thermal damage. This takes place for instance when the person is exposed to a very bright light pulse, shorter than $20 \mu \mathrm{s}$. Usually, when the rise in temperature is at least $10^{\circ} \mathrm{C}$ above the physiological temperature, then thermal damage occurs, which leads to thermal denaturation of many proteins [13]. Wavelengths between $800 \mathrm{~nm}$ to $1400 \mathrm{~nm}$ (which are heat) are able to oxidize or decompose photopigment moleculesł

2. Photochemical damage when photons can destroy chemical bonds (in organic molecules; for instance, the cornea and the lens absorb part of the infrared radiation mainly water bands at $980 \mathrm{~nm}, 1200 \mathrm{~nm}$, and $1430 \mathrm{~nm}$ [13]). "Photochemical damage occurs when light is absorbed by a chromophore and leads to the formation of an electronically excited state of that molecule, which then undergoes either chemical transformation itself and/or interacts with other molecules, leading to chemical changes of both interacting molecules, or to a transfer of the excitation energy to the other molecules" [13]. It needs to be highlighted that photochemical damage does 
not cause a substantial increase in the temperature of the tissue. Electromagnetic energy of the violet and blue ( $400-500[\mathrm{~nm}])$ wavelengths (near UV), is sufficient to destroy photopigment molecules.

The wavelengths' effect of photochemical damage to the retina is present in Table 1.

Table 1 . The wavelengths' effect of photochemical damage to the retina

\begin{tabular}{|c|c|c|c|}
\hline \multicolumn{4}{|c|}{ Wavelength [nm] } \\
\hline 463 & 500 & 520 & $630-720$ \\
\hline $\begin{array}{c}\text { Irreversible damage to S } \\
\text { cones }\end{array}$ & $\begin{array}{c}\text { Damage to } \\
\text { rods }\end{array}$ & $\begin{array}{c}\text { Reversible damage to M } \\
\text { cones }\end{array}$ & $\begin{array}{c}\text { Reversible damage to L } \\
\text { cones }\end{array}$ \\
\hline
\end{tabular}

There is a photomechanical (or photoacoustic) damage when for instance a pulse laser produces a thermoelastic pressure wave. Light energy is absorbed faster than the relaxation of the mechanical wave.

Sunlight (the solar irradiance) may damage the human retina. In the midday, sun energy varies between 1.5 and $122\left[\mathrm{~W} / \mathrm{cm}^{2}\right]$. So, even several minutes of exposure are sufficient to damage the retina (photochemical effect). Energetic UV sun radiation is absorbed by oxygen and generates the ozone.

Due to the effects of ultraviolet radiation on living organisms, the UV spectrum can be divided into three subgroups:

- UV-A - wavelength: 315-400 [nm], photon energy: 3.10-3.94 [eV],

- UV-B - wavelength: 280-315 [nm], photon energy: 3.94-4.43 [eV],

- UV-C - wavelength: 100-280 [nm], photon energy: 4.43-12.4 [eV].

The most harmful radiation to humans is radiation from the entire range of $\mathrm{C}$ and most of the B range. Happily, UV-C is completely absorbed, and UV-B is mostly absorbed by the ozone layer and atmosphere. UV-A is not absorbed by the ozone layer and as a result, about 97\% of UV-A light reaches the Earth's surface [14].

\section{Light sources}

The light sources can be divided according to the emitting light process on natural (objects found in nature that produce light) and artificial (Human made objects that produce light) objects. Natural sources of light include sunlight, the stars, volcanoes, meteorological lightning, light of fire and biochemical sources. Artificial light sources can be classified as an incandescent bulbs, a halogen lamp, gaseous discharge light (metal halide, fluorescent tube, compact fluorescent tube), LED (light-emitting diodes) light (red LED, green LED, blue LED, RGB LED, white LED). Despite the variety of natural sources of light, the most significant impact on humanity is had by the nearest star - the sun. Solar radiation is the main source of energy on earth. We may say that the earliest form of artificial light used to illuminate an area were campfires and torches. The next step was to use oil lamps. Later, candles were invented. With time, electric lamps improved lighting of the darkness. We want to present the different light sources and compare their spectra with the with that of the sun. 


\section{Experiment}

We carry out the spectra absorption measurements using a spectrometer HR4000CGUVNIR Ocean's Optics. This spectrometer has the ability to perform spectroscopic measurements, such as absorbance, reflectance, and emission in the range from $200 \mathrm{~nm}$ to $1100 \mathrm{~nm}$. Light is transmitted into the spectrometer through an optical fiber. The spectrometer measures the amount of light and transforms the collected data into digital information.

All presented spectra are obtained by use. We divided them into two types: a dome-shaped spectrum (a continuous spectrum) and the multiple peaks spectrum (a discrete spectrum superimposed on a continuous spectrum).

Figure 3 shows the daylight spectrum. This spectrum has a dome shape. On the domeshape base, we do not see any additional peaks. It can be concluded that this is the most optimal light source. Daylight spectrum has a shape similar to that of the solar spectrum. However, passing through the atmosphere, the light is absorbed and scattered, and it final form is ragged. In this article, we will consider this spectrum as reference.

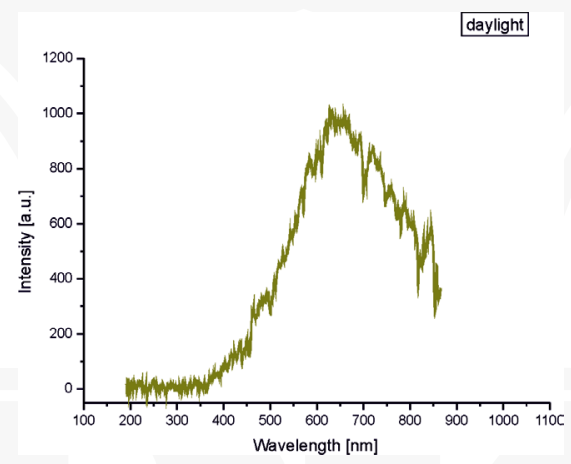

Fig. 3. Daylight spectrum

\section{Candle spectrum}

Candles emit light of a continuous range of wavelength (frequencies). The candle spectrum is smoothed with the single potassium (K) maximum at $780 \mathrm{~nm}$ (Fig. 4).

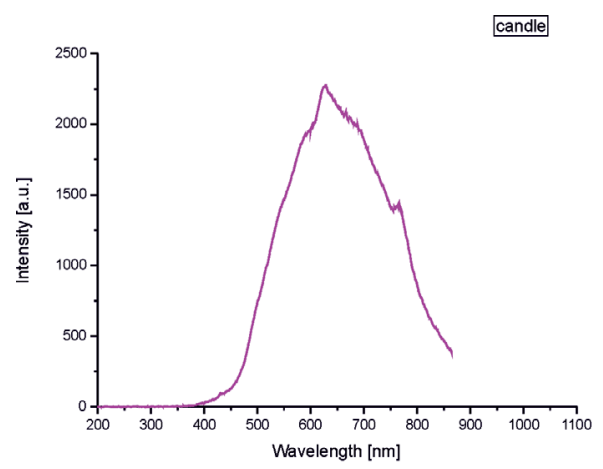

Fig. 4. Candle spectrum 


\section{Kerosene lamp spectrum}

Kerosene lamp emits light of a continuous range of wavelength. The spectrum is also smoothed (Fig. 5), but we have to keep in mind that luminous efficacy of a kerosene flame is very low.

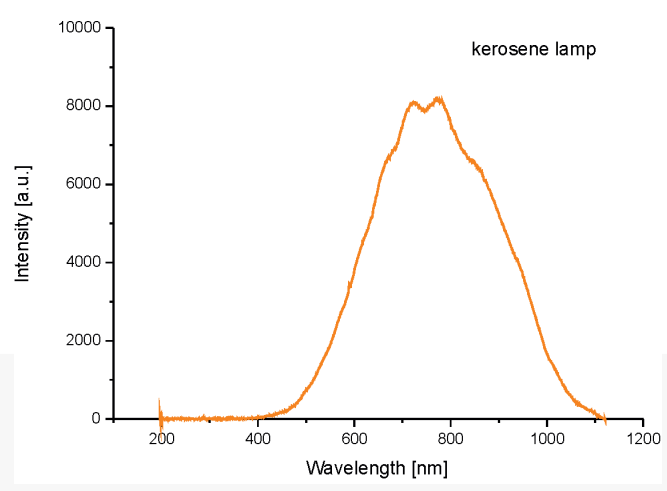

Fig. 5. Kerosene lamp

\section{Incandescent bulb spectrum}

Incandescent bulbs produce a continuous electromagnetic spectrum. The nature of this form of radiation may be explained by Planck's law. In Figure 6, we present the incandescent bulb spectra for three different total power lamps.

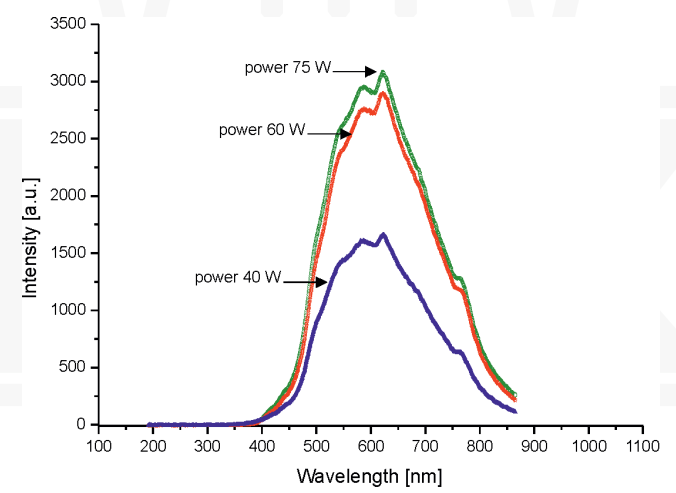

Fig. 6. Incandescent bulb spectra (three bulbs of different power consumption)

Looking at the incandescent bulb spectra, we may argue that the emitted light does not disrupt the natural sensitivity of the human eye in the whole range of wavelengths. However, we should keep in mind that incandescent bulbs are inefficient energetically; less than 5\% of the electric energy is converted into visible light [14]. On the other hand, incandescent bulbs are irreplaceable in applications where accurate color reproduction is important. The spectrum emitted from an incandescent bulb reproduces colors almost perfectly. The colour temperature is $2100-3000 \mathrm{~K}$. In Figure 7, one can compare the three normalized spectra of sunlight, incandescent bulb and candle. 


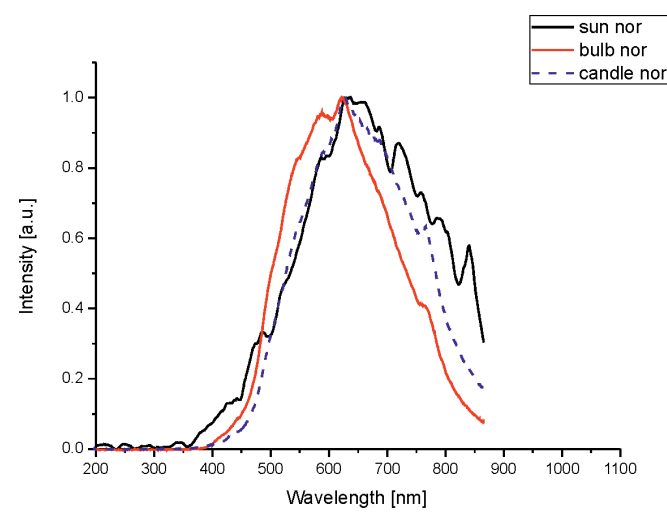

Fig. 7. Three normalized spectra of sunlight, incandescent bulb and candle

\section{Mercury-vapor spectrum}

A mercury-vapor lamp is a type of discharge lamp in which light is produced by an electrical discharge in mercury vapor. The spectrum consists of several very thin lines (Fig. 8). Mercury-vapor lamps are characterized by an arc discharge. In these lamps, there is a strobe effect. In mercury-vapor lamps, less than $10 \%$ of the energy is converted into visible light. The rest of the energy is converted to heat and UV.

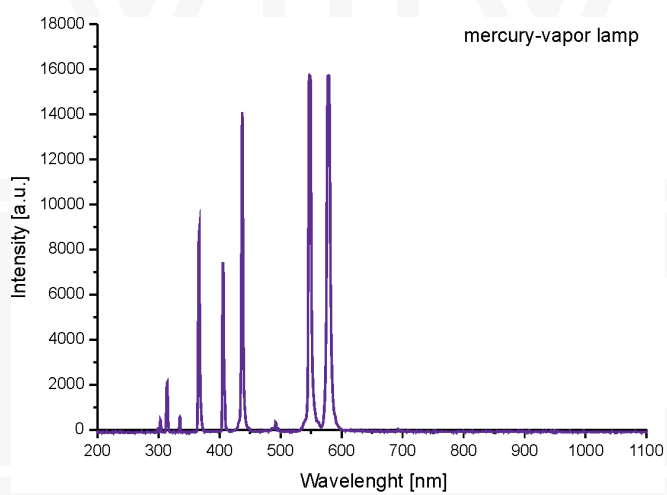

Fig. 8. The mercury-vapor lamp spectrum

Using the phosphor, the part of UV radiation is converted into white light, which in turn gives a better color reproduction. The colour temperature is about $4800 \mathrm{~K}$ with phosphor and $6600 \mathrm{~K}$ without phosphor. We would like to emphasize that the spectrum is not domeshaped.

\section{Halogen bulb spectrum}

Halogen bulbs are also an incandescent emitter. They are filled with a small amount of a halogen (for example iodine, which is at a higher pressure: 7-8 atm), preventing the darkening of the bubble from the inside. They operate at a higher temperature. Halogen forms a chemical compound with 
tungsten. This compound circulates together with the gas in the bulb. Then, it decomposes into tungsten and halogen because of the heat of the filament. As a result takes place transfer of tungsten particles from the bulb onto the filament. This is the so-called halogen regenerative cycle. Like an incandescent light emitter, the halogen lamp radiates a continuous spectrum of light; from ultraviolet to infrared (Fig. 9). What is worth noting is the fact that the spectrum of halogen lamp (2800-3400 [K]) is closer to sunlight than the standard tungsten $(2000-3500[\mathrm{~K}])$. The spectrum is shifted toward blue. Seeing that the lamp can operate at a higher temperature, it emits some UV radiation. The doped-quartz glass of halogen bulbs blocks UV.

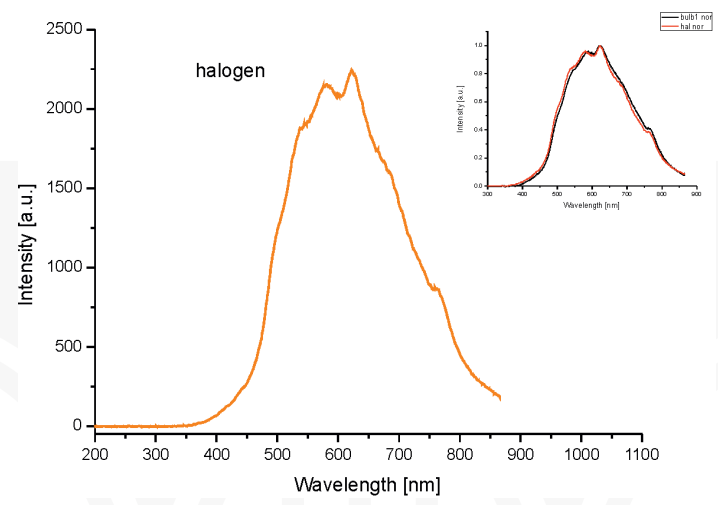

Fig. 9. Halogen bulb spectrum (Inset: normalized spectra of incandescent bulb and halogen lamp)

\section{Fluorescent tube spectrum}

Fluorescent tubes (fluorescent lamps) produce light differently than incandescent bulbs. An electric current flowing through an argon gas and a small amount of mercury vapor in tube generate invisible (short-wave) ultraviolet light. This light arouses luminophor on the inside of the tube to emit a visible light. Colour temperature is $2300-6800 \mathrm{~K}$. The color reproducibility is more than $80 \%$.

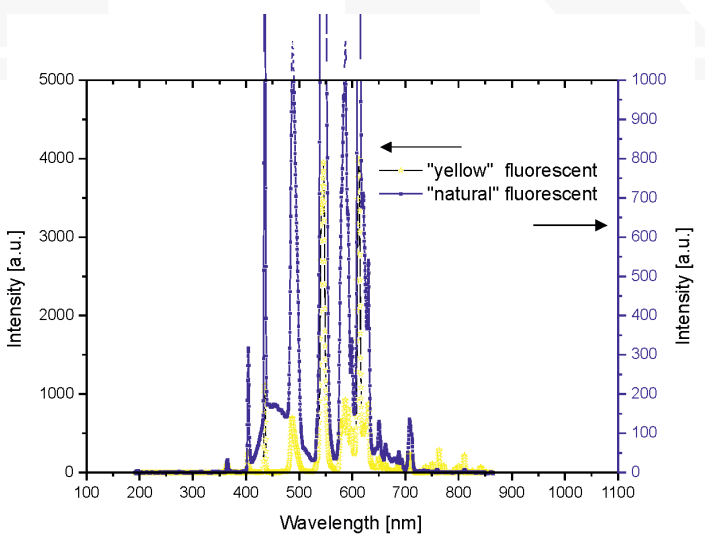

Fig. 10. Fluorescent tubes spectra - left scale "yellow" fluorescent tube, right scale "natural sunshine" fluorescent tube 
The fluorescent spectra presented in Figure 10 are of the multiple peaks type. A discrete spectrum superimposed on a continuous base is visible for "natural sunshine" fluorescent tube (right scale). This shape results from the physical mechanism of radiation: the electrons acquiring energy and then losing it. According to the laws of quantum mechanics, when the electrons lose energy, they emit a specific electromagnetic wave. As one can see for the selected wavelength (selected color), the intensity increases several times. This means that the selected photoreceptor should reduce its sensitivity. However, the human eye sensitivity regulation mechanism affects the whole eye and not individual photoreceptors. In Figure 11, one can compare normalized spectra of sunlight, incandescent bulb and fluorescent tube.

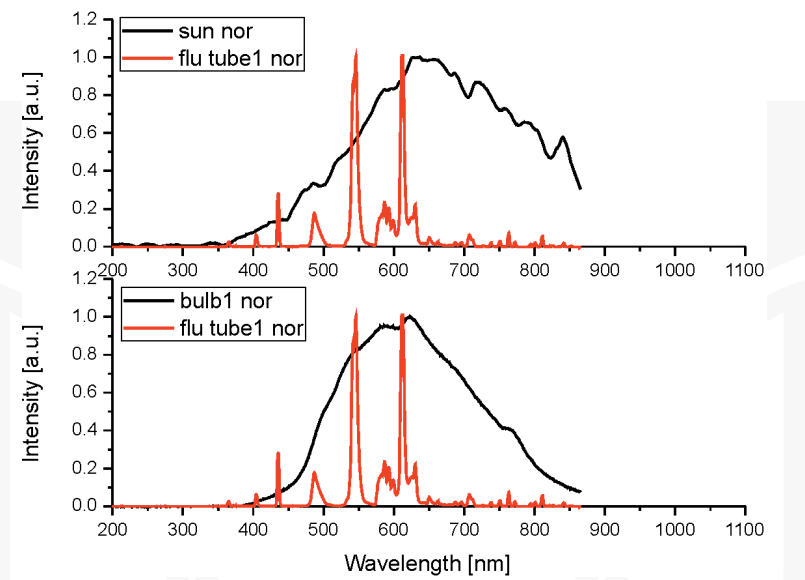

Fig. 11. Normalized spectra of sunlight, incandescent bulb and fluorescent tube

An extreme case of peak type radiation is laser (Light Amplification by Stimulated Emission of Radiation) (Fig. 12). Lasers are not considered as a source of light in everyday use - they are rather used as a tool in science, medicine and technology. On any device that uses laser, a warning is placed about the possibility of eye damage.

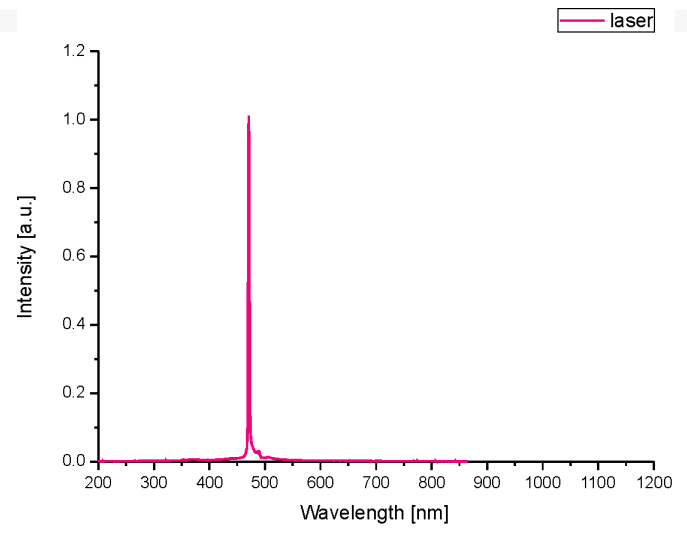

Fig. 12. Spectrum of laser 


\section{Xenon lamp spectrum}

We need to mention that many of today's cars use xenon headlights. Xenon lamp spectrum is of multiple peaks type. It brings all the negatives of this kind of lamps. Besides, there are some very strong emission lines in the near infrared, roughly in the region of 800-1000 [nm] (Fig. 13).

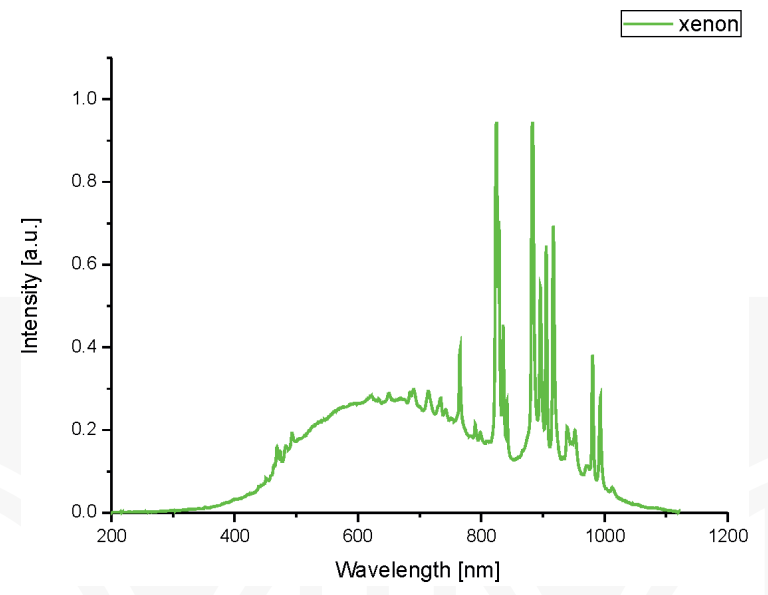

Fig. 13. Xenon lamp spectrum

\section{LED bulb spectrum}

Currently, the best solution seems to be new lighting technology, namely LED bulbs. In recent years, the popularity of LED (Light Emitting Diodes) bulbs increased. Their spectrum is explicitly marked by a broad maximum (Fig. 14). Light emitting diode is a semiconductor light source. Controlled by voltage, the p-n junction diode, releasing recombine electronselectron holes energy in the form of light (photons); this is electroluminescence effect. The color of the light (the energy of the photon) is specified by the band gap energy of the semiconductor.

Nevertheless, LED bulbs can emit white light (WLED). There are two ways to reach it. Firstly, the WLED lamp may consist of red, green and blue LED sources - these sources combined emit white light base on Maxwell's color triangle. Secondly, a more popular method is to use a blue LED light sources and the phosphor coating, which change the light spectrum. By using several layers, the light spectrum can be compared to that emitted by the sun.

We should keep in mind that the principle of bulb-type LED operation is based on the Graetz bridge. So, one can expect pulsation. In Fig. 15, the pulsation of the light intensity of the WLED is presented.

However, there is still a lot of controversy. The European Commission report (Health Effects of Artificial Light) saying that LED blue light causes a photochemical risk to the eye; "Blue light is (...) recognized as being harmful and dangerous for the retina, as a result of cellular oxidative stress (...)" - citation $[15,16]$. The other main risk is from glare. The report say that, for indoor lighting, it is generally agreed that luminance higher than $10,000 \mathrm{~cd} / \mathrm{m}^{2}$ causes visual 
discomfort whatever the position of the lighting unit in the field of vision. Because the emission surfaces of LEDs are highly-concentrated point sources, the luminance of each individual source can be 1000 times higher than the discomfort level. The level of direct radiation from this type of source can therefore easily exceed the level of visual discomfort [17]. To produce white light, LED electronics must emit light at short wavelengths, which makes them potential sources for suppressing melatonin at night $[18]$.

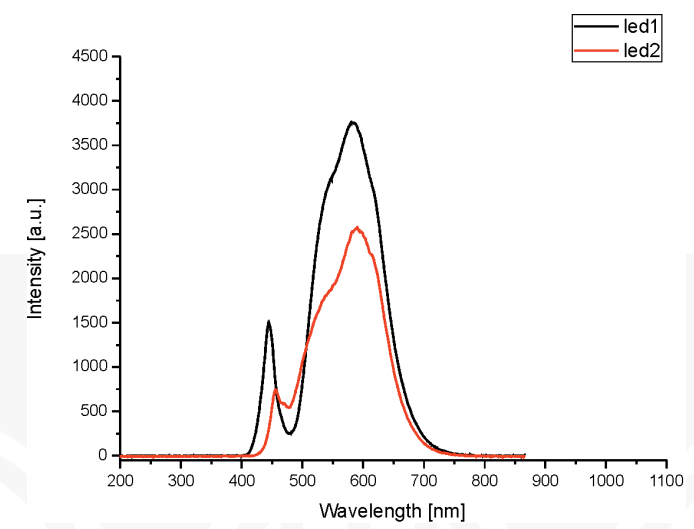

Fig. 14. Spectra of commercially available LEDs from different manufacturers

In the opinion of the authors, LEDs have many advantages over incandescent light sources like lower energy consumption, longer lifetime, faster switching and dome-shape spectrum.

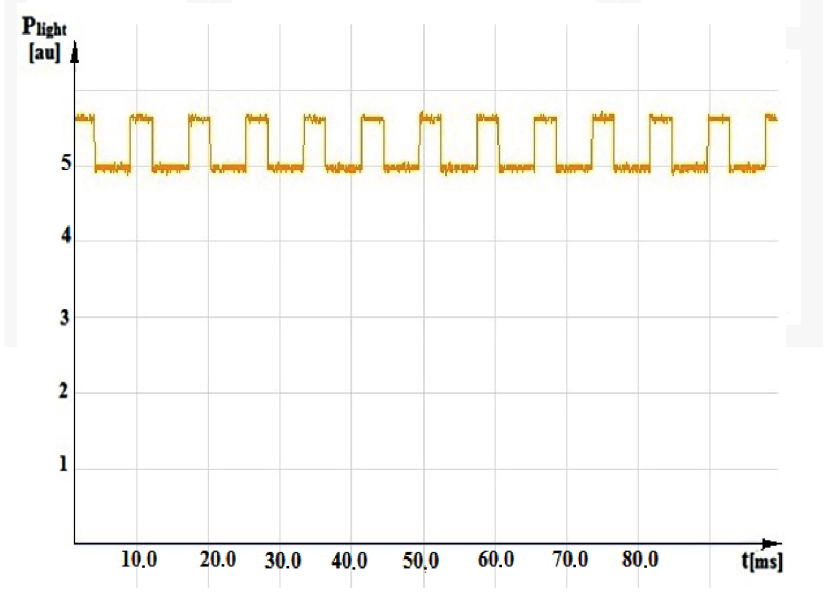

Fig. 15. Pulsation of the light intensity of the WLED (frequency $\omega=100 \mathrm{~Hz}$ )

Nowadays, LEDs are often applied to highlight different kinds of displays, such as televisions, computer screens, lighted wallpaper or cell phones. Light Emitting Diodes are now used as car headlamps, traffic signals, street lights and architecture lighting. LEDs are used in commercial and home areas. 
Considering the rapid development of the LED technology (organic light-emitting diodes (OLEDs), quantum dot LEDs), we may expect an elimination of the defects of LEDs.

\section{Summary}

In this paper, we wanted to point out that, in addition to the traditional assessment of the sources of light (which is largely quantitative assessment) based mostly on power consumption, one should consider, even qualitatively, the health effects of artificial light. This effect is partially encoded in (or related to) the shape of the spectrum. Estimation of this effect is difficult because it requires extensive research on a large set of people (on a large population) for a long time. The authors believe that the best shape of the spectrum for the human eye is the one that best approximates the spectrum of the sun (dome-shaped like). Each additional high-intensity narrow peak endangers the human eye. The human eye has no mechanism for a selective reduction of the amount of incident light.

However, avoidance of the negative effects of new technologies can bring in long-term, measurable and positive economic effects.

\section{References}

[1] Ham W.T Jr., Mueller HA., Ruffolo J.J Jr., Clarke A.M., Sensitivity of the retina to radiation damage as a function of wavelength, Photochem Photobiol, Vol. 29, 1979, 735-743.

[2] Grieve K., Roorda A., Intrinsic Signals from Human Cone Photoreceptors Investigative, Ophthalmology \& Visual Science, 49, 2008, 713-719.

[3] Brainard G.C., Hanifin J.P., Greeson J.M., Byrne B., Glickman G., Gerner G., Gerner E., Rollag M.D., Action Spectrum for Melatonin Regulation in Humans: Evidence fora Novel Circadian Photoreceptor, J. Neuro, 21, 2001, 6405-6412.

[4] Provencio I., Jiang G., De Grip W.J., Hayes W.P., Rollag M.D., Melanopsin: An opsin in melanophores, brain, and eye, Proc. Nat. Acad. Sci., 95, 1998, 340-345.

[5] He S., Dong W., Deng Q. Weng S., Sun W., Seeing more clearly: recent advances in understanding retinal circuitry, Science, 302, 2003, 408-411.

[6] Fritzsche H., Poirier E., A Systematic Neutron Reflectometry Study on Hydrogen Absorption in Thin Mg1-xAlx Alloy Films, Canadian Journal of Physics, 88, 2010, 10-15.

[7] Gross H., Blechinger F., Achtner B., Handbook of Optical Systems, Vol. 4, Wiley-VCH, 2008.

[8] Wilkinson M.H.F., Schut F., Digital Image Analysis of Microbes, John Wiley and Sons, 1998.

[9] Barten P.G.J., Contrast Sensitivity of the Human Eye and Ist Effect on Image Quality, SPIE Press, 1999.

[10] Young M., Optics and lasers, Springer, 1993. 
[11] Dyer S.A., Survey of Instrumentation and Measurement, Wiley-IEEE, 2001.

[12] Northrop R.B., Analysis and Application of Analog Electronic Circuits to Biomedical Instrumentation, CRC Press, 2004.

[13] Good G.W., Light and Eye Damage American Optometric Association, http:// physics. stackexchange.com/posts/158274/revisions (access: 25.06.2016).

[14] Levine M.W., Levine \& Shefner's Fundamentals of sensation and perception, Oxford 2006.

[15] Rüchard E., Światto widzialne i niewidzialne, PWN, Warszawa 1962 (in Polish).

[16] LEDs Magazine, Light and human health: LED risks highlighted, http://www. ledsmagazine.com/articles/2010/11/light-and-human-health-led-risks-highlighted. html (access: 18.05.2016).

[17] European Commission, Health and Consumers, Health Effects of Artificial Light, http:// ec.europa.eu/health/scientific_committees/opinions_layman/artificial-light/en/ index.htm (access: 18.05.2016).

[18] Good G.W., Light and Eye Damage, American Optometric Association, December 2014.

[19] Wood B., Rea M.S., Plitnick B., Figueiro M.G., Light level and duration of exposure determine the impact of self-luminous tablets on melatonin suppression, Applied Ergonomics, 44, 2013, 237-240. 